\title{
Faktor Yang Berpengaruh Terhadap Loyalitas Pelanggan Minimarket OMI Koperasi Universitas PGRI Palembang
}

\author{
Ilhamsyah ${ }^{1}$, Agus Mulyani ${ }^{2}$, Oktariansyah ${ }^{3}$ \\ ${ }^{1}$ Fakultas Ekonomi dan Bisnis Universitas PGRI Palembang, ilhamsyahcakep2015@gmail.com \\ ${ }^{2}$ Fakultas Ekonomi dan Bisnis Universitas PGRI Palembang, agusmulyani@univpgri-palembang.ac.id \\ ${ }^{3}$ Akuntansi, F.Ekonomi dan Bisnis, Univ.PGRI Palembang, rianbro82@univpgri-palembang.ac.id
}

\begin{abstract}
ABSTRAK
Tujuan penelitian untuk mengetahui faktor pelayanan (X1), barang yang ditawarkan (X2), suasana (X3) dan harga (X4) yang berpengaruh terhadap loyalitas pelanggan $(Y)$ serta faktor yang paling dominan terhadap loyalitas pelanggan sebagai variabel terikat. Populasi dihitung melalui rata-rata jumlah pelanggan setiap bulannya yaitu 1.244 sedangkan sampel menggunakan Metode Accidental Sampel sebanyak 97, teknik pengumpulan data adalah kuesioner dan wawancara. Dengan cara menyebar angket dan bertanya secara secara langsung kepada konsumen. Pengujian Instrumen yaitu uji validitas instrumen, uji reliabilitas. Metode analisis yaitu uji normalitas data, uji model terdiri uji heteroskedastisitas. uji multikolinieritas, Model Analisis yaitu analisis jalur yang dihitung dengan dua persamaan struktural yaitu persamaan regresi yang menunjukkan hubungan yang dihipotesiskan, uji koefisien untuk melihat tingkat signifikansi masing-masing koefisien regresi. Hasil Penelitian ini nantinya berapa besar pengaruh faktor signifikan terhadap loyalitas pelanggan dan faktor yang dominan terhadap loyalitas pelanggan di Minimarket OMI Koperasi Univ. PGRI Palembang.
\end{abstract}

Kata kunci: Pelayanan, Barang, Suasana, Harga, Loyalitas Pelanggan

\begin{abstract}
The research objective was to determine the service factor (X1), goods offered (X2), atmosphere (X3) and price (X4) which affect customer loyalty $(Y)$ as well as the most dominant factor on customer loyalty as the dependent variable. The population was counted by the average number of customers each month, namely 1,244, while the sample used the Accidental Method. The sample was 97, the data collection techniques were questionnaires and interviews. By distributing questionnaires and asking directly to consumers. Instrument testing, namely the instrument validity test, reliability test. The method of analysis is the data normality test, the model test consists of the heteroscedasticity test. multicollinearity test, Analysis Model, namely path analysis calculated by two structural equations, namely the regression equation which shows the hypothesized relationship, the coefficient test to see the significance level of each regression coefficient. The results of this study will be how much the influence of significant factors on customer loyalty and dominant factors on customer loyalty in Minimarket OMI Koperasi Univ. PGRI Palembang.
\end{abstract}

Keywords: Service, Goods, Atmosphere, Price, Customer Loyalty

\section{A. PENDAHULUAN}

Salah satu cara untuk meningkatkan dan mempertahankan konsumen adalah memiliki loyalitas dari konsumen. Loyalitas ditujukan kepada suatu perilaku, yang bertujuan untuk pembelian ruti yang didasarkan pada unit pengambilan keputusan. Loyalitas pelanggan memberikan profitabilitas bagi perusahaan karena pelanggan yang loyal dapat menunjukkan sikap dan perilaku yang positif serta dapat memberikan rekomendasi yang positif sehingga dapat menjadi alat promosi bagi perusahaan tersebut. Minimarket yang memiliki pelanggan yang loyal akan mendapatkan keuntungan seperti konsumen kurang sensitif terhadap harga, 
meluangkan waktu lebih untuk produk perusahaan, konsumen akan memiliki perasaan positif terkait dengan produk yang dikeluarkan perusahaan tersebut.

Bagi konsumen loyalitas akan memberikan manfaat dengan cara memudahkan konsumen dalam mengambil keputusn pembelian, proses pencarian informasi yang lebih cepat dan adanya kepuasan. Selain itu loyalitas konsumen juga dapat memberikan manfaat dalam mengurangi resiko pembelian, memberikan manfaat ekonomi, meningkatkan efesiensi dalam proses pengambilan keputusan.

Adanya berbagai manfaat dari loyalitas pelanggan baik bagi konsumen dan produsen tentu membuat topik loyalitas menjadi penting untuk diteliti, dengan alasan bahwa atmosfer toko sangat mempengaruhi pada bentuk pembelian dan kepuasan pelanggan.

Selain atmosfir toko promosi penjualan juga dianggap sebagai faktor pengaruh yang kedua dalam terciptanya loyalitas pelanggan hal ini dikarenakan bahwa berdasarkan penelitian yang penulis akan lakukan dengan mengetahui data, tingkat dan prilaku loyal konsumen maka retailer dapat digunakan sebagai pembuat strategi promosi. Adanya konsumen yang loyal dapat menciptakan pembelian kembali dengan mengadakan insentif pembelian dan diharapkan nantinya dapat menjadi salah satu bentuk promosi bagi konsumen baru

\section{B. KAJIAN TEORI}

\section{Faktor-Faktor Bauran Pemasaran}

Membangun bisnis eceran perlu adanya strategi-strategi dalam meningkatkan kualitas suatu bisnis ecera. Strategi yang digunakan yaitu salah satunya bauran eceran yang harus sesuai dengan bisnis eceran yang digeluti sehingga membawa dampak positif terhadap perkembagan bisnis tersebut. Adapun tujuan dari bauran eceran tersebut adalah sebagai berikut :

a. Untuk mencapai target perusahaan

b. Untuk memperlancar distribusi barang kepada konsumen akhir.

c. Agar dapat membandingkan dengan peretail lainnya melalui strategi-strategi yang digunakan.

d. Untuk memperlancar proses penjualan sehingga menambah jumlah konsumen.

e. Untuk mempermudah konsumen mendapatkan barang kebutuhan sehari-hari.

Suatu bisnis eceran dapat berkembang dengan baik jika strategi- strategi yang digunakan telah diterapkan dengan baik pula. Selain tujuan dari bauran eceran adapun manfaat yang didapat perusahaan, diantaranya sebagai berikut :
a. Target perusahaan dapat tercapai
b. Kegiatan perusahaan dapat terkoordinir dengan baik
c. Membentuk citra baik perusahaan dimata konsumen
d. Menambah omzet penjualan perusahaan
e. Memberi masukan yang baik untuk perkembangan perusahaan

Dari definisi yang telah dikemukakan oleh Henri Ma'ruf (2015:124), enam variabel bauran eceran diantaranya meliputi:

\section{a. Lokasi (Location)}

Lokasi adalah faktor yang sangat penting dalam bauran pemasaran eceran. 
Pada lokasi yang tepat, sebuah gerai atau toko akan lebih sukses dibanding toko lainya yang berlokasi kurang strategis, meskipun keduanya menjual produk yang sama. Sebelum sebuah toko atau tempat berbelanja didirikan, langkah pertama adalah mempelajari suatu area agar investasi yang ditanamkan dapat menguntungkan. Menurut Hendri Ma'ruf (2015:124), ada beberapa faktor yang harus dipertimbangkan dalam mengevaluasi area perdagangan eceran, diantaranya sebagai berikut :

1) Besar populasi dan karakteristiknya, jumlah penduduk dan kepadatan suatu wilayah meliputi faktor dalam mempertimbangkan suatu area perdagangan eceran. Jumlah peretail yang sama di dua wilayah tetapi kepadatan penduduknya berbeda akan menyebabkan omzet yang rendah pada peretail di wilayah yang kurang padat penduduknya.

2) Kedekatan dengan pemasok, pemasok mempunyai pengaruh pada peretail dalam hal kecepatan penyediaan merchandise, kualitas produk yang terjaga, biaya pengiriman, dan lain-lain. Jumlah pemasok sebisa mungkin ada beberapa supaya tidak terjadi ketergantungan pada satu atau dua pemasok saja.

3) Basis ekonomi, basis ekonomi yang dimaksud di sini adalah indistri daerah setempat, potensi pertumbuhan, fluktuasi karena faktor musiman, dan fasilitas keuangan. Industri yang bervariasi akan mempunyai pengaruh yang yang berbeda dibandingkan dengan indistri yang terkonsentrasi.

4) Keterbatasan tenaga kerja, tenaga kerja yang diperhatikan adalah pada suatu tingkat, yaitu dari tingkat administratif dan lapangan hingga management trainee dan manajerial. Management trainee adalah pada lulusan perguruan tinggi yang memulai karier di perusahaan retail pada tingkat staf, dan diproyeksikan untuk menjadi tenaga pemimpin. Tenaga manejerial adalah para assisten manager atau manager bahkan general manager yang siap direktur dan siap kerja (tidak seperti management trainee yang harus dilatih lebih dulu).

5) Situasi persaingan, pertumbuhan luas toko yang sejalan dengan pertumbuhan permintaan pasar (yaitu besar belanja total penduduk setempat) berarti semua perusahaan retail setempat tumbuh secara stabil atau secara tetap. Jika banyak pihak membuka gerai retail dengan asumsi merebut pasar sebesar-besarnya, maka kemungkinan yang terjadi adalah kejenuhan pasar, yaitu terlalu banyak paritel dibandingkan total belanja konsumen.

6) Fasilitas promosi, adanya media massa seperti surat kabar dan radio akan memfasilitasi kegiatan promosi peretail. Juga kesiapan sarana pendukung seperti biro iklan, production house, dan pembuat barang souvenir yang memperlancar kegiatan promosi perlu mendapat perhatian.

7) Kesediaan lokasi toko, faktor bagi suatu area perdagangan dan hal- hal yang terkait dengan lokasi adalah jumlah lokasi serta jenisnya, akses pada masing-masing lokasi, perpeluang kepemilikan atau leasing, pembatasan zona perdagangan, dan biaya- biaya terkait. 
8) Hukum dan peraturan, hukum dan peraturan perlu diperhatikan khususnya jika terdapat Perda (Peraturan Daerah) yang tidak terdapat di daerah lain.

\section{b. Barang dagangan (Marchandise)}

Marchandise merupakan produk-produk yang dijual peretail dalam gerainya, sedangkan merchandise adalah kegiatan pengadaan barang-barang yang sesuai dengan bisnis yang dijalani toko (produk berbasis makanan, pakaian, barang kebutuhan rumah dan produk umum lainnya) untuk disediakan dalam toko pada jumlah, waktu dan harga yang sesuai untuk mencapai sasaran toko atau perusahaan retail.

Para pelanggan selalu berharap untuk memenuhi apa yang dibutuhkan dan diinginkannya disetiap toko, kebutuhan dan keinginan pelanggan sangat beragam dan toko diharapkan dapat memenuhinya. Fungsi pengelolaan barang dagangan (merchandise) merupakan fungsi yang harus diberi prioritas, bagaimanapun efektif dan efisiennya bagian lain, bila urusan barang dagangan salah, bila urusan barang dagangan salah, maka hampir dapat dipastikan sukses akan sulit diraih.

\section{c. Harga (Price)}

Penetapan harga adalah yang paling krusial dan sulit diantara unsur-unsur dalam bauran pemasaran retail lainnya, dan harga merupakan satu-satunya unsur dalam pemasaran eceran yang akan mendatangkan laba bagi peretail. Sebuah toko dapat menjadi terkenal karena harga jual yang ditetapkan cukup murah atau harga jual yang di tetapkan merupakan harga pasti. Berdasarkan hal itu, pengecer harus dapat menetapkan harga yang tepat untuk barangbarang yang akan dijualnya, sehingga kelancaran penjualan barang akan lebih terjamin. Semua pengecer senantiasa berkeinginan menetapkan harga yang tinggi dengan volume penjualan yang tinggi pula, namun kedua hal ini sulit di terapkan secara bersamaan.

Penetapan harga berkaitan dengan aspek-aspek laba, pelanggan, pasar dan persaingan, pengadaan barang dagangan, citra kualitas merek yang berbeda dan hukum peraturan, yang akan di uraikan sebagai berikut:

1) Harga berkaitan dengan maksimalisasi laba, setiap peretail atau perusahaan pedagang eceran, ingin memaksimalisasikan laba. Laba dapat dicapai dalam jangka pendek dan jangka panjang.

2) Harga berkaitan dengan pelanggan, memaksimalisasikan laba adalah salah satu sisi dari selembar mata uang, sisi lainnya adalah kepuasan konsumen. Tujuan perusahaan adalah kepuasan pelanggan melalui operasional perusahaan yang akan memberi laba yang patut.

3) Harga berkaitan dengan pasar dan perdagangan, faktor pasar atau persaingan merupakan faktor penting yang amat mempengaruhi penetapan harga.Untuk suatu peretail yang hendak memperluas pembeli dalam suatu wilayah atau dalam suatu segmen disebut sebagai penetrasi pasar, penetapan harga rendah atau harga bersaing dilakukan.

4) Harga berkaitan dengan pengadaan barang dagangan. barang persediaan yang masih banyak dan agak lambat penjualannya padahal tanggal kadaluarsanya tinggal beberapa bulan lagi, mengharuskan tindakan penjualan sesegera mungkin. Itu hanya bisa dilakukan dengan harga diskon atau menjual barang dengan beberapa paket.

5) Harga berkaitan dengan citra kualitas, sebagian besar masyarakat 
mempunyai anggapan bahwa terdapat kolelasi erat antara harga dan kualitas. Harga yang rendah dianggap pertanda kualitasnya rendah sebaliknya harga tinggi mencerminkan kualitas tinggi.

6) Harga berkaitan dengan merek yang berbeda, produk dari merek-merk yang berbeda dapat diberi label harga yang berbeda menurut:

$\checkmark$ Merek terunggul yang diberi label termahal

$\checkmark$ Merek pesaing atau merek sendiri dengan label harga sedang, dan

$\checkmark$ Merek dengan harga terendah

7) Harga berkaitan dengan hukum dan peraturan

Saat ini dapat dikatakan masih sangat minim hukum dan peraturan yang mengatur penetapan harga barang dan jasa eceran. Ini berarti para peretail mempunyai ruang gerak yang cukup bebas dalam menetapkan harga. Namun patokan umum berlaku yaitu kepatutan berdasarkan etika bisnis khususnya dari sudut pandang konsumen yaitu value for money.

\section{d. Promosi (Promotion)}

Komunikasi sebagai dasar promosi bertujuan mendorong target market untuk mau menjadi pembeli bahkan menjadi pelanggan setia. Esensi dari komunikasi pemasatan ini adalahbagaimana kita dapat menyampaikan apa yang kita tawarkan kepada konsumen dapat di terima dengan baik. Komunikasi pemasaran tidak hanya membuat pelanggan tertarik dan ingin membeli, namun komunikasi pemasaran juga bisa menciptakan citra tertentu yang kita sesuaikan dengan pasaran sasaran.

Menurut Kotler yang di kutip dari buku Taufik (2015:85) menyatakan bahwa ada beberapa elemen penting dalam komunikasi pemasaran yaitu periklanan, promosi penjualan, penjualan tatap muka (personal selling), kehumasan (public relation) dan pemasaran langsung.

\section{e. Pelayanan (Service)}

Menurut Kotler (2012:427) yang di alih bahasakan oleh Susanto menyatakan bahwa "Pelayanan setiap tindakan atau keterampilan yang dapat ditawarkan oleh apapun juga yang pada dasrnya tidak berwujud dan tidak menyebabkan kepemilikan sesuatu, pelayanan dapat disertakan dalam produk yang berbentuk fisik".

Aspek pelayanan semakin hari semakin nyata perannya, secara umum pelayanan tersebut meliputi bagai mana kecepatan melayani pelanggan sebelum berbelanja dan pada saat berbelanja. Dengan demikian usaha eceran harus mampu mencoba sedemikian rupa agar pelayanan yang dirasakan pelanggan meningkat serta sesuai dengan kehendak pelanggan. Unsur pelayanan adalah unsur yang memiliki peranan penting dalam persaingan nonharga dengan pengecer-pengecer lain.

Unsur-unsur pelayanan menjadi nyata bagi perusahaan dalam bersaing dengan para pesaingnya karena unsur pelayanan sangat sulit ditiru oleh pesaing. Menurut Kotler (2012:446) yang di alih bahasakan oleh Susanto membagi pelayanan menjadi dua bagian yaitu pelayanan primer dalam usaha eceran antara lain adalah pembayaran kredit, pengantaran, penanganan keluhan, penanganan parkir, ruang istirahat termasuk toilet. Sedangkan yang termasuk pelayanan pendukung antara lain: pembungkusan, informasi lokasi barang, konsultasi dan informasi pembelian, tempat penitipan barang. Pelayanan 
adalah salah satu faktor pembeli nilai nilai tambah bagi peretail, atau peretail dapat memilih kombinasi ragam prodak dan tingkat pelayanan sebagai positioning.

\section{f. Suasana dalam toko (Atmosphere)}

Jika iklan bertujuan memberitahu, menarik, memikat atau mendorong konsumen, untuk datang ke gerai dan untuk membeli barang, maka suasana toko atau atmosphere dalam gerai atau toko berperan penting mengikat pembeli, membuat nyaman mereka dalam memilih barang belanjaan, dan mengingatkan mereka produk apa yang perlu dimiliki baik untuk keperluan pribadi maupun keperluan rumah tangga. Gerai kecil yang tertata rapi dan menarik akan lebih mengundang pembeli di bandingkan gerai yang di atur biasa saja tapi bersih lebih menarik dari pada gerai yang tidak diatur sama sekali dan tampak kotor.

Suasana dalam gerai menggambarkan moment of truth, yaitu situasi langsung yang di rasakan konsumen pada saat berbelanja. Jika seting dari suasana itu optimal maka peretail (dengan gerai yang di kunjungi konsumen) akan dapat menyentuk emosi konsumen dan memberi pengalaman berbelanja. Desain toko yang baik akan menarik banyak konsumen untuk datang, desain toko merupakan strategi penting untuk menciptakan suasana yang akan membuat pelanggan merasa betah berada dalam suatu gerai atau toko. Derai toko, yaitu desain interior yang mencakup tata letak rak-rak barang, aksesoris toko, dan desain eksterior mencakup lay-out, pintu masuk, dan jalan masuk.

Menurut Berman dan Evans $(2017 ; 105)$ untuk bentuk toko yang berdasarkan Store Based Retail terdapat strategi bauran penjualan eceran terdiri dari lokasi departement store (store location) prosedur pembelian atau pelayanan (operating procedures), produk atau barang yang ditawarkan (good offered), harga barang (pricing tactics), suasana departement store (store atmosphere), karyawan (custumer services), dan metode promosi (promotional methods).

\section{Loyalitas Pelanggan}

Tujuan dari memasarkan suatu produk oleh semua perusahaan adalah untuk memiliki pelanggan yang loyal, loyalitas pelanggan dapat dibentuk melalui beberapa tahapan, mulai dari mencari calon pelanggan potensial sampai dengan advocate customers yang akan membawa keuntungan bagi perusahaan dan membuat rasa kepuasan dari seorang pelanggan.

Menurut Griffin (2015:113) menjelaskan bahwa Loyalitas lebih mengacu pada wujud perilaku dari unit-unit pengambilan keputusan untuk melakukan pembelian secara terus menerus terhadap barang atau suatu jasa perusahaan yang dipilih.

Kotler (2017:139), menyatakan loyalitas konsumen adalah komitmen yang dipegang secara mendalam untuk membeli atau mendukung kembali produk atau jasa yang disukai di masa depan meski pengaruh situasi dan usaha pemasaran berpotensi.

Selanjutnya Griffin (2015:5) berpendapat bahwa seorang pelanggan dikatakan setia atau loyal apabila pelanggan tersebut menunjukkan perilaku pembelian secara teratur atau terdapat suatu kondisi dimana mewajibkan pelanggan membeli paling sedikit dua kali dalam selang waktu tertentu. Upaya memberikan kepuasan pelanggan dilakukan untuk mempengaruhi sikap pelanggan, sedangkan konsep loyalitas pelanggan lebih berkaitan dengan perilaku pelanggan daripada sikap dari 
pelanggan. Griffin (2015:77) menjelaskan bahwa ada 7 tahap dalam loyalitas seperti yang dijelaskan berikut:

a. Suspects, mencakup semua orang yang mungkin akan membeli jasa atau barang perusahaan.

b. Prospects, adalah orang-orang yang memiliki kebutuhan akan produk atau jasa tertentu, dan mempunyai kemampuan untuk membelinya.

c. Disqualified Prospects, yaitu prospek yang telah ditelitimengetahui keberadaan jasa atau barang tertentu, tetapi tidak mempunyai kebutuhan akan barang/jasa tersebut atau tidak mempunyai kemampuan untuk membeli barang atau jasa tersebut.

d. First time customers, yaitu pandangan ketika akan membeli untuk yang pertama kalinya.

e. Repeat Costumer, yaitu pelanggan yang telah melakukan pembelian suatu produk sebanyak dua kali atau lebih.

f. Cilents, yaitu pelanggan membeli semua jasa atau barang yang ditawarkan, yang mereka butuhkan.

g. Advocates, Seperti halnya clients, advocates membeli seluruh jasa barang yang ditawarkan yang ia butuhkan, serta melakukan pembelian secara teratur.

Menurut Tjahyadi (2016:96), bahwa faktor-faktor yang mempengaruhi loyalitas pelanggan terhadap suatu produk dilihat dari kepuasan pelanggan dan kulitas pelayanan:

a. Kepuasan Pelanggan, merupakan pengukuran antara harapan pelanggan dengan kenyataan yang mereka terima atau rasakan.

b. Kualitas Pelayanan, adalah tingkat keunnggulan yang diharapkan dan pengendalian atas tingkat keunggulan tersebut dalam memenuhi keinginan pelanggan.

Menurut Griffin (2015:77) terdapat empat jenis loyalitas yang muncul bila keterikatan rendah dan tinggi diklasifikasi silang dengan pola pembelian ulang, yang rendah dan tinggi. Adapun jenis - jenis loyalitas konsumen yaitu :

a. Tanpa Loyalitas, ada beberapa konsumen yang tidak mengembangkan loyalitas atau kesetiaan kepada suatu produk maupun jasa tertentu.

b. Loyalitas yang lemah (Inertia Loyality), merupakan sebuah jenis loyalitas konsumen yang dimana adanya keterikatan yang rendah dengan pembelian ulang yang tinggi.

c. Loyalitas Tersembunyi (Laten Loyality), jenis loyalitas tersembunyi merupakan sebuah kesetiaan atau keterikatan yang relatif tinggi yang disertai dengan tingkat pembelian ulang yang rendah.

d. Loyalitas Premium (Premium Loyalty), merupakan yang terjadi bilamana suatu tingkat keterikatan tinggi yang berjalan selaras dengan aktivitas pembelian kembali.

Menurut Creswell (2013:14), bahwa terdapat empat faktor yang mempengaruhi persepsi dan ekpektasi konsumen, yaitu sebagai berikut: 
a. Didengar dari pelanggan lain (Word of mouth communication), konsumen memilih perusahaan yang diharapkan dapat memberikan pelayanan dengan kualitas tinggi berdasarkan rekomendasi relasi.

b. Kebutuhan individu (Personal Needs), ekpektasi pelanggan sangat tergantung drai karakteristik individu/kebutuhan pribadi.

c. Pengalaman masa lalu (Post Experience), menggunakan pengalaman masa lalu sebagai alasan untuk meningkatkan ekspektasi konsumen

d. Komunikasi dengan pihak eksternal (External communication), perusahaan memberikan layanan dengan memberikan pesan-pesan secara langsung maupun tidak langsung kepada konsumen.

Menurut Kotler (2017:88) bahwa Loyalitas konsumen merupakan komitmen seorang konsumen terhadap suatu pasar berdasarkan sikap positif dan tercermin dalam pembelian ulang secara konsisten.

Terdapat empat macam dimensi loyalitas pelanggan menurut Griffin (2015:31), yaitu:

a. Melakukan pembelian ulang secara teratur (Makes regular repeat purchase), komsumen melakukan pembelian secara continue pada suatu produk tertentu.

b. Melakukan pembelian lini produk yang lainnya (Purchases across product and service lines), konsumen tidak hanya membeli jasa dan produk utama tetapi konsumen juga membeli lini produk dan jasa dari perusahaan yang sama

c. Memberikan referensi pada orang lain (Refers others), dimana konsumen melakukan komunikasi dari mulut ke mulut (word of mouth) berkenaan dengan produk tersebut.

d. Menunjukkan kekebalan terhadap tarikan dari pesaing (Demonstrates in immunity to the pull of the competition) misalnya tidak mudah terpengaruh oleh bujukan pesaing.

Penelitian terkait yang dilakukan peneliti terdahulu adalah adalah sebagai berikut ini:

a. Yavas dan Babakus (2013:75), penelitian menyatakan ada berbagai hal terkait dengan anteseden dari loyalitas pelanggan seperti persepsi kualitas, harga dan lingkungan toko. Lingkungan toko meliputi interior, ekterior dan desain operasional yang menjadi karakteristik toko, hal ini danggap menjadi salah satu alasan konsumen bersikap loyal walaupun hal tersebut hanya bersifat khusus yaitu berlaku bagi sigmen pasar tertentu. Hali penelitian menunjukan bahwa atmosfer toko seperti warna, pencahayaan, dekorasi interior, musik dan wewangian dapat mempengaruhi keputusan konsumen dan citra toko tersebut

b. Wijayanto (2013), Adanya berbagai promosi penjualan seperti undian dan membership (keanggotaan) dinilai merupakan cara yang paling mempengaruhi loyalitas pelanggan. Pengaruh promosi penjualan terbukti memiliki pengaruh terhadap loyalitas konsumen

\section{METODE PENELITIAN}

Metode penelitian dalam penelitian ini adalah penelitian asosiatif (Sugiyono, 2017:6). Variabel bebas yaitu atmosfer toko dan promosi penjualan serta loyalitas pelanggan sebagai variabel terikat.

Data Penelitian terdiri dari: 
1) Jenis Data, penelitian ini menggunakan data Cross Section (Sugiyono, 2017:23).

2) Sumber Data adalah:

$>$ Data Primer.

$>$ Data Sekunder

Tabel Definisi Operasional Variabel Penelitian

\begin{tabular}{|c|c|c|c|c|}
\hline No & Variabel & Definisi Variabel & Indikator & $\begin{array}{c}\text { Item } \\
\text { Pertanyaan }\end{array}$ \\
\hline 1 & Pelayanan $\left(\mathrm{X}_{1}\right)$ & $\begin{array}{l}\text { Seluruh rangkaian perasi } \\
\text { yang diberikan Minimarket } \\
\text { OMI guna memudahkan } \\
\text { konsumen berbelanja }\end{array}$ & $\begin{array}{l}\text { 1.Informasi } \\
\text { 2.Empati } \\
\text { 3.Penanganan Keluhan } \\
\text { 4.Pengembalian Barang }\end{array}$ & $\begin{array}{l}1-2 \\
3-4 \\
5-6 \\
7-8\end{array}$ \\
\hline 2 & $\begin{array}{l}\text { Barang } \quad \text { Yang } \\
\text { Ditawarkan }\left(X_{2}\right)\end{array}$ & $\begin{array}{l}\text { Perencanaan dan } \\
\text { pengendalian barang } \\
\text { dalam pembelian dan } \\
\text { penjualan barang dan jasa } \\
\text { untuk mencapai tujuan } \\
\text { telah ditentukan Minimarket } \\
\text { OMI }\end{array}$ & $\begin{array}{l}\text { 1.Ragam merk } \\
\text { 2.Ragam barang } \\
\text { 3.Persediaan } \\
\text { 4.Kualitas }\end{array}$ & $\begin{array}{l}1-2 \\
3-4 \\
5-6 \\
7-8\end{array}$ \\
\hline 3 & $\begin{array}{l}\text { Atmosfer } \\
\left(X_{3}\right)\end{array}$ & $\begin{array}{lr}\text { merupakan } & \text { kegiatan } \\
\text { merancang lingkungan } \\
\text { pembelian melalui } \\
\text { penataan barang dan } \\
\text { fasilitas fisik lainnya yang } \\
\text { dapat menpengaruhi emosi } \\
\text { konsumen untuk } \\
\text { melakukan pembelian. } \\
\text { (Berman: 2017:545) }\end{array}$ & $\begin{array}{l}\text { 1. Exterior } \\
\text { 2. Interior } \\
\text { 3.Store layout } \\
\text { 4. Interior Display }\end{array}$ & $\begin{array}{l}1-2 \\
3-4 \\
5-6 \\
7-8\end{array}$ \\
\hline 4 & $\begin{array}{l}\text { Promosi } \\
\text { Penjualan }\left(\mathrm{X}_{4}\right)\end{array}$ & $\begin{array}{l}\text { insentif jangka pendek } \\
\text { untuk mendorong } \\
\text { pembelian atau penjualan } \\
\text { suatu produk atau jasa. } \\
\text { (Kotleer:2017:204) }\end{array}$ & $\begin{array}{l}\text { 1.Sampel produk } \\
\text { 2. Kupon } \\
\text { 3.Pengembalian tunai } \\
\text { 4. Harga khusus } \\
\text { 5.Premi } \\
\text { 6.Barang khusus iklan } \\
\text { 7.Undian produk } \\
\text { 8.Membership }\end{array}$ & $\begin{array}{l}1 \\
2 \\
3 \\
4 \\
5 \\
6 \\
7 \\
8\end{array}$ \\
\hline 5 & $\begin{array}{l}\text { Loyalitas } \\
\text { Pelanggan (Y) }\end{array}$ & $\begin{array}{l}\text { Komitmen yang dipegang } \\
\text { secara mendalam oleh } \\
\text { konsumen untuk membeli } \\
\text { kembali produk atau jasa di } \\
\text { masa depan. } \\
\text { (Griffin:2015:77) }\end{array}$ & $\begin{array}{l}\text { 1. Pembelian ulang } \\
\text { 2. Pembelian antar produk } \\
\text { lainnya. } \\
\text { 3. Mereferensikan pada } \\
\text { orang lain } \\
\text { 4.kekebalan pada pesaing }\end{array}$ & $\begin{array}{l}1-2 \\
3-4 \\
5-6 \\
7-8\end{array}$ \\
\hline
\end{tabular}

\section{Populasi dan Sampel}

Adapun populasi dalam penelitian ini adalah konsumen yang berkunjung atau berbelanja pada Minimarket OMI Koperasi Keluarga Universitas PGRI Palembang:

Tabel Data Pelanggan

\begin{tabular}{ccc}
\hline No & \multicolumn{1}{c}{ Bulan } & Jumlah \\
1 & Agustus 2019 & 2.910 \\
2 & September 2019 & 2.741 \\
\hline
\end{tabular}




\begin{tabular}{|c|c|c|}
\hline 3 & Oktober 2019 & 2.549 \\
\hline 4 & Desember 2019 & 2.458 \\
\hline & Jumlah & 10.658 \\
\hline
\end{tabular}

Data populasi dalam penelitian ini dihitung melalui rata-rata jumlah konsumen setiap bulannya:

$$
\text { Populasi }(\mathrm{N})=\frac{10.658}{4}=2.664,5 .=2.665 \text { pelanggan }
$$

Sedangkan sampel menggunakan Metode Accidental Sample yaitu sampel yang diambil dengan cara kebetulan pada saat konsumen sedang berbelanja atau berkunjung pada Minimarket OMI Koperasi Keluarga Univ. PGRI Palembang. Menurut Sugiyono (2017:75), adapun rumus yang digunakan Rumus Slovin sebagai berikut:

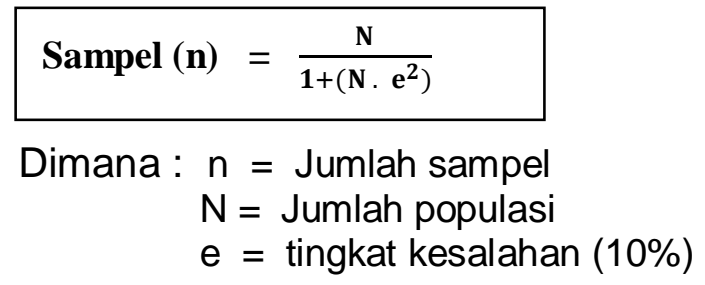

Sampel $(\mathrm{n})=\frac{2.665}{1+\left(2.665 \times 0,1^{2}\right)}=96,33 \approx 97$ pelanggan.

\section{Pengujian Instrumen}

1. Uji Validitas Instrumen, valid berarti instrumen tersebut dapat digunakan untuk mengukur apa yang seharusnya diukur (Sugiyono, 2017:177).

a) Jika $r$ hitung $>r$ tabel product moment, data tersebut valid.

b) Jika $r$ hitung $\leq r$ tabel product moment, berarti data tersebut tidak valid.

2. Uji Reliabilitas Instrumen, adalah suatu ukuran yang menunjukkan sejauh mana hasil pengukuran tetap konsisten bila dilakukan pengukuran berulangkali terhadap gejala dan alat ukur yang sama (Sugiyono, 2017:183).

\section{Metode Analisis}

1. Uji Normalitas Data, digunakan untuk melihat apakah sebaran data hasil penelitian terdistribusi secara normal atau tidak Alqifari (2016:123). Untuk mengetahui apakah data-data, variabel independent dan dependent mempunyai distribusi normal atau tidak. Model regresi yang baik adalah memiliki distribusi normal atau mendekati normal. Menurut Riadi (2016:168) Data terdistribusi normal dalam model regresi dilihat dengan Komlmogorof Smirnof Test I, dengan $\alpha=0,05$ atau $5 \%$.

2. Uji Model

a. Uji Heteroskedastisitas, Alqifari (2016:137), bertujuan untuk mengetahui dalam model regresi terjadi ketidaksamaan varians dari residual pengamatan ke pengamatan yang lain. Jika data membentuk pola tertentu, seperti titik-titik yang membentuk pola tertentu dan teratur (bergelombang, melebar kemudian menyempit) maka telah terjadi heterokedastisitas. Sebaliknya jika tidak ada pola yang jelas serta titik-titik menyebar di atas dan di bawah angka 0 pada sumbu Y, maka tidak terjadi heterekedastisitas.

b. Uji Multikolinieritas, bertujuan untuk menguji apakah model regresi ditemukan adanya korelasi antara variabel bebas (independent). Jika variabel bebas saling berkorelasi, maka variabel-variabel ini tidak orthogonal, dapat dilihat dari (a) 
nilai tolerance dan lawannya (b) Variance Inflation Factor (VIP). Kedua ukuran ini menunjukkan setiap variabel bebas manakah yang dijelaskan oleh variabel lainnya, dasar acuannya jika nilai toleransi $>0,10$ dan nilai VIF $<10$, maka, disimpulkan bahwa tidak ada multikolinearitas antar variabel independen dalam model regresi.

\section{Model Analisis}

Berdasarkan permasalahan dan hipotesis yang diajukan, alat teknis analisis statistika yang digunakan adalah analisis jalur yang dihitung dengan dua persamaan struktural yaitu persamaan regresi yang menunjukkan hubungan yang dihipotesiskan, persamaan tersebut (Supranto 2016: 205) adalah:

$$
\mathrm{Y}=\beta_{1} X_{1}+\beta_{2} X_{2}+\beta_{3} X_{3}+\beta_{4} X_{4}+e_{1}
$$

Keterangan:

$Y=$ Loyalitas pelanggan

$B_{1}=$ Koefisien jalur dari pelayanan

$B_{2}=$ Koefisien jalur dari barangyang ditawarkan

$B_{3}=$ Koefisien jalur dari suasana

$B_{4}=$ Koefisien jalur dari harga

$\mathrm{X}_{1}=$ Pelayanan

$\mathrm{X}_{2}=$ Barang yang ditawarkan

$\mathrm{X}_{3}=$ Suasana

$\mathrm{X}_{4}=$ Harga

$\mathrm{e}_{2}=$ Nilai kekeliruan taksiran standar (standar error)

\section{Uji Koefisien}

Uji koefisien jalur digunakan untuk melihat tingkat signifikansi masing-masing koefisien regresi.

\section{Hasil Hipotesis 1}

HO: Tidak terdapat pengaruh signifikan pelayanan terhadap loyalitas pelanggan Minimarket OMI Koperasi Univ. PGRI Palembang

$\mathrm{Ha}$ : Terdapat pengaruh signifikan pelayanan terhadap loyalitas pelanggan Minimarket OMI Koperasi Univ. PGRI Palembang

\section{Hasil Hipotesis 2}

H0: Tidak terdapat pengaruh signifikan barang terhadap loyalitas pelanggan Minimarket OMI Koperasi Univ. PGRI Palembang

$\mathrm{Ha}$ : Terdapat pengaruh signifikan barang terhadap loyalitas pelanggan Minimarket OMI Koperasi Univ. PGRI Palembang

\section{Hasil Hipotesis 3}

H0: Tidak terdapat pengaruh signifikan suasana terhadap loyalitas pelanggan Minimarket OMI Koperasi Univ. PGRI Palembang

Ha: Terdapat pengaruh signifikan suasana terhadap loyalitas pelanggan Minimarket OMI Koperasi Univ. PGRI Palembang

\section{Hasil Hipotesis 4}

H0: Tidak terdapat pengaruh signifikan harga terhadap loyalitas pelanggan Minimarket OMI Koperasi Univ. PGRI Palembang

Ha: Terdapat pengaruh signifikan harga terhadap loyalitas pelanggan Minimarket OMI Koperasi Univ. PGRI Palembang 


\section{Hasil Hipotesis 5}

H0: Tidak terdapat pengaruh signifikan pelayanan, barang, suasana dan harga terhadap loyalitas pelanggan Minimarket OMI Koperasi Universitas PGRI Palembang

D. HASIL DAN PEMBAHASAN

1. Hasil Pengujian Instrumen

\section{a. Hasil Pengujian Validitas}

\begin{tabular}{cccc}
\multicolumn{4}{c}{ Tabel Hasil Uji Validitas Variabel Pelayanan $\left(\mathbf{X}_{\mathbf{1}}\right)$} \\
\hline $\begin{array}{c}\text { Item } \\
\text { Indikator }\end{array}$ & $\begin{array}{c}\text { Corrected Item- } \\
\text { Total Correlation }\end{array}$ & $\begin{array}{c}\mathrm{r} \text { Tabel } \\
\mathrm{n}=97\end{array}$ & Kesimpulan \\
\hline $\mathrm{X} 1.1$ & 0,488 & 0,361 & Valid \\
\hline X1.2 & 0,391 & 0,361 & Valid \\
\hline X1.3 & 0,449 & 0,361 & Valid \\
\hline X1.4 & 0,403 & 0,361 & Valid \\
\hline X1.5 & 0,581 & 0,361 & Valid \\
\hline X1.6 & 0,543 & 0,361 & Valid \\
\hline X1.7 & 0,475 & 0,361 & Valid \\
X1.8 & 0,442 & 0,361 & Valid
\end{tabular}

Tabel Hasil Uji Validitas Variabel Barang Yang Ditawarkan ( $\left.\mathbf{X}_{2}\right)$

\begin{tabular}{cccc}
\hline $\begin{array}{c}\text { Item } \\
\text { Indikator }\end{array}$ & $\begin{array}{c}\text { Corrected Item- } \\
\text { Total Correlation }\end{array}$ & $\begin{array}{c}\mathrm{r} \text { Tabel } \\
\mathrm{n}=97\end{array}$ & Kesimpulan \\
\hline X2.1 & 0,530 & 0,361 & Valid \\
X2.2 & 0,408 & 0,361 & Valid \\
\hline X2.3 & 0,488 & 0,361 & Valid \\
\hline X2.4 & 0,548 & 0,361 & Valid \\
\hline X2.5 & 0,477 & 0,361 & Valid \\
X2.6 & 0,606 & 0,361 & Valid \\
X2.7 & 0,606 & 0,361 & Valid \\
X2.8 & 0,442 & 0,361 & Valid \\
\hline
\end{tabular}

Tabel Hasil Uji Validitas Variabel Suasana $\left(\mathbf{X}_{3}\right)$

\begin{tabular}{cccc}
\hline $\begin{array}{c}\text { Item } \\
\text { Indikator }\end{array}$ & $\begin{array}{c}\text { Corrected Item- } \\
\text { Total Correlation }\end{array}$ & $\begin{array}{c}\mathrm{r} \text { Tabel } \\
\mathrm{n}=97\end{array}$ & Kesimpulan \\
\hline $\mathrm{X} 1.1$ & 0,581 & 0,361 & Valid \\
$\mathrm{X} 1.2$ & 0,543 & 0,361 & Valid \\
$\mathrm{X} 1.3$ & 0,475 & 0,361 & Valid \\
\hline X1.4 & 0,530 & 0,361 & Valid \\
X1.5 & 0,408 & 0,361 & Valid \\
X1.6 & 0,488 & 0,361 & Valid \\
X1.7 & 0,548 & 0,361 & Valid \\
\hline X1.8 & 0,477 & 0,361 & Valid \\
\hline
\end{tabular}




\begin{tabular}{cccc}
\multicolumn{4}{c}{ Tabel Hasil Uji Validitas Variabel Harga $\left(\mathbf{X}_{\mathbf{4}}\right)$} \\
\hline $\begin{array}{c}\text { Item } \\
\text { Indikator }\end{array}$ & $\begin{array}{c}\text { Corrected Item- } \\
\text { Total Correlation }\end{array}$ & $\mathrm{r}$ Tabel & \\
$\mathrm{n}=97$ & Kesimpulan \\
\hline X2.1 & 0,442 & 0,361 & Valid \\
\hline X2.2 & 0,408 & 0,361 & Valid \\
\hline X2.3 & 0,488 & 0,361 & Valid \\
\hline X2.4 & 0,548 & 0,361 & Valid \\
\hline X2.5 & 0,488 & 0,361 & Valid \\
\hline X2.6 & 0,548 & 0,361 & Valid \\
\hline X2.7 & 0,606 & 0,361 & Valid \\
\hline X2.8 & 0,442 & 0,361 & Valid \\
\hline
\end{tabular}

\begin{tabular}{|c|c|c|c|}
\hline $\begin{array}{c}\text { Item } \\
\text { Indikator }\end{array}$ & $\begin{array}{l}\text { Corrected Item- } \\
\text { Total Correlation }\end{array}$ & $\begin{array}{l}\text { r Tabel } \\
n=97\end{array}$ & Kesimpulan \\
\hline Y.1 & 0,383 & 0,361 & Valid \\
\hline Y.2 & 0,442 & 0,361 & Valid \\
\hline Y.3 & 0,452 & 0,361 & Valid \\
\hline Y.4 & 0,487 & 0,361 & Valid \\
\hline Y.5 & 0,462 & 0,361 & Valid \\
\hline Y.6 & 0,545 & 0,361 & Valid \\
\hline Y.7 & 0,414 & 0,361 & Valid \\
\hline Y.8 & 0,411 & 0,361 & Valid \\
\hline
\end{tabular}

\section{b. Hasil Pengujian Reliabilitas}

Tabel Hasil Uji Reliabilitas

\begin{tabular}{clccc}
\hline No & Variabel & $\begin{array}{c}\text { Cronbach's } \\
\text { Alpha }\end{array}$ & $\begin{array}{c}\text { Nilai } \\
\text { Alpha }\end{array}$ & $\begin{array}{c}\text { Hasil Uji } \\
\text { Reliabilitas }\end{array}$ \\
\hline 1 & Pelayanan $\left(\mathrm{X}_{1}\right)$ & 0,793 & 0,70 & Reliabel \\
\hline 2 & Barang Yang Ditawarkan $\left(\mathrm{X}_{2}\right)$ & 0,807 & 0,70 & Reliabel \\
\hline 3 & Suasana $\left(\mathrm{X}_{3}\right)$ & 0,835 & 0,70 & Reliabel \\
\hline 4 & Harga $\left(\mathrm{X}_{4}\right)$ & 0,801 & 0,70 & Reliabel \\
\hline 5 & Loyalitas Pelanggan $(\mathrm{Y})$ & 0,747 & 0,70 & Reliabel \\
\hline
\end{tabular}




\section{Deskriptif Statistik Data}

Tabel Hasil Deskriptif Statistik Data Penelitian

\begin{tabular}{lccccc}
\hline N & Pelayanan & $\begin{array}{c}\text { Barang Yang } \\
\text { Ditawarkan }\end{array}$ & Suasana & Harga & $\begin{array}{c}\text { Loyalitas } \\
\text { Pelanggan }\end{array}$ \\
\hline Missing & 97 & 97 & 97 & 97 & 97 \\
Mean & 0 & 0 & 0 & 0 & 0 \\
Std. Error of mean & 2,846 & 2,796 & 2,857 & 2,836 & 2,406 \\
Median & 0,055 & 0,058 & 0,067 & 0,045 & 0,053 \\
Mode & 2,830 & 2,835 & 2,841 & 2,820 & 2,830 \\
Std. Deviation & 2,100 & 2,113 & 2,113 & 2,150 & $2,060^{\text {a }}$ \\
Variance & 0,524 & 0,533 & 0,535 & 0,514 & 0,500 \\
Skewness & 0,275 & 0,265 & 0,290 & 0,265 & 0,250 \\
Std. Error of. & 0,233 & 0,230 & 0,245 & 0,223 & 0,255 \\
ErrSkewness & 0,255 & 0,265 & 0,268 & 0,245 & \\
Kurtosisi & & & & & \\
Std. Error of Kurtosis & $-0,873$ & $-0,866$ & $-0,873$ & $-0,863$ & $-0,376$ \\
Range & 0,506 & 0,511 & 0,506 & 0,516 & 0,506 \\
Minimum & 2,230 & 2,232 & 2,230 & 2,210 & 2,210 \\
Maximum & 1,840 & 1,848 & 1,840 & 1,820 & 1,350 \\
Sum & 4,070 & 4,087 & 4,070 & 4,069 & 3,560 \\
\hline
\end{tabular}

Karakteristik Responden

Tabel Distribusi Responden Berdasarkan Jenis Kelamin

\begin{tabular}{llcc}
\hline No & $\begin{array}{l}\text { Jenis } \\
\text { Kelamin }\end{array}$ & $\begin{array}{c}\text { Jumlah } \\
\text { (Orang) }\end{array}$ & Persentase(\%) \\
\hline 1 & Laki-laki & 40 & 42,24 \\
\hline 2 & Perempuan & 51 & 57,76 \\
\hline & Total & $\mathbf{9 7}$ & $\mathbf{1 0 0}$ \\
\hline
\end{tabular}

Tabel Distribusi Responden Berdasarkan Umur

\begin{tabular}{cccc}
\hline No & $\begin{array}{c}\text { Rentang Usia } \\
\text { Responden (Tahun) }\end{array}$ & $\begin{array}{c}\text { Jumlah } \\
\text { (Orang) }\end{array}$ & $\begin{array}{c}\text { Persentase } \\
(\%)\end{array}$ \\
\hline 1 & $15-20$ & 25 & 25,77 \\
\hline 2 & $21-25$ & 30 & 30,93 \\
\hline 3 & $26-30$ & 10 & 10,31 \\
\hline 4 & $31-35$ & 10 & 10,31 \\
\hline 5 & $36-40$ & 10 & 10,31 \\
\hline 6 & Lebih dari 40 tahun & 12 & 12,37 \\
\hline \multicolumn{4}{r}{} \\
\hline
\end{tabular}

Tabel Distribusi Responden Berdasarkan Pekerjaan

\begin{tabular}{llcc}
\hline No & Pekerjaan & $\begin{array}{c}\text { Jumlah } \\
\text { (Orang) }\end{array}$ & $\begin{array}{c}\text { Persentase } \\
\text { (\%) }\end{array}$ \\
\hline 1 & Pegawai/Pengelola & 15 & 15,46 \\
\hline 2 & Pegawai Honorer & 15 & 15,46 \\
3 & Mahasiswa & 25 & 25,78 \\
\hline 4 & Pelajar & 30 & 30,93 \\
\hline 5 & dll & 12 & 12,37 \\
\hline Total & $\mathbf{9 7}$ & $\mathbf{1 0 0}$ \\
\hline
\end{tabular}




\section{Deskripsi Jawaban Responden}

Tabel Distribusi Frekuensi Variabel Suasana $\left(\mathrm{X}_{3}\right)$

\begin{tabular}{|c|c|c|c|c|c|c|}
\hline No & Pernyataan & $\frac{\text { STS }}{(1)}$ & $\frac{\text { TS }}{(2)}$ & $\frac{N}{(3)}$ & $\frac{S}{(4)}$ & $\frac{\text { SS }}{(5)}$ \\
\hline & Exterior & & & & & \\
\hline 1 & $\begin{array}{l}\text { Minimarket OMI memiliki tampilan } \\
\text { yang menarik pelanggan untuk } \\
\text { masuk ke minimarket. }\end{array}$ & $\begin{array}{c}0 \\
(0 \%)\end{array}$ & $\begin{array}{c}3 \\
(3,4 \%)\end{array}$ & $\begin{array}{c}21 \\
(23,6 \%)\end{array}$ & $\begin{array}{c}47 \\
(52,8 \%)\end{array}$ & $\begin{array}{c}18 \\
(20,2 \%)\end{array}$ \\
\hline 2 & $\begin{array}{l}\text { Minimarket } \\
\text { kebersihan fasilitas fisik. }\end{array}$ & $\begin{array}{c}0 \\
(0 \%)\end{array}$ & $\begin{array}{c}5 \\
(56 \%)\end{array}$ & $\begin{array}{c}22 \\
24,7 \%)\end{array}$ & $\begin{array}{c}46 \\
(51,7 \%)\end{array}$ & $\begin{array}{c}16 \\
(18 \%)\end{array}$ \\
\hline \multirow[t]{2}{*}{3} & Interior & & & & & \\
\hline & $\begin{array}{l}\text { Minimarket OMI memilik ir } \\
\text { untuk menarik bagi pelangga }\end{array}$ & $\begin{array}{c}0 \\
(0 \%)\end{array}$ & $\begin{array}{c}2 \\
(2,2 \%)\end{array}$ & $\begin{array}{c}21 \\
(23,6 \%)\end{array}$ & $\begin{array}{c}44 \\
(49,4 \%)\end{array}$ & $\begin{array}{c}22 \\
(24,7 \%)\end{array}$ \\
\hline 4 & $\begin{array}{l}\text { Interior yang dimiliki membuat } \\
\text { pelanggan betah dan aman untuk } \\
\text { membeli produk yang diinginkan. }\end{array}$ & $\begin{array}{c}0 \\
(0 \%)\end{array}$ & $\begin{array}{c}3 \\
(3,4 \%)\end{array}$ & $\begin{array}{c}17 \\
(19,1 \%)\end{array}$ & $\begin{array}{c}47 \\
(52,8 \%)\end{array}$ & $\begin{array}{c}22 \\
(24,7 \%)\end{array}$ \\
\hline \multirow[t]{2}{*}{5} & Store Layout & & & & & \\
\hline & $\begin{array}{l}\text { Barang telah tersusun dengan } \\
\text { rapi. }\end{array}$ & $\begin{array}{c}0 \\
(0 \%)\end{array}$ & $\begin{array}{c}1 \\
(1,1 \%)\end{array}$ & $\begin{array}{c}22 \\
(24,7 \%)\end{array}$ & $\begin{array}{c}52 \\
(58,4 \%)\end{array}$ & $\begin{array}{c}14 \\
(15,7 \%)\end{array}$ \\
\hline 6 & $\begin{array}{l}\text { Pembeli dengan mudah } \\
\text { mendapatkan dengan mudah } \\
\text { akan barang yang mereka cari. }\end{array}$ & $\begin{array}{c}0 \\
(0 \%)\end{array}$ & $\begin{array}{c}0 \\
(0 \%)\end{array}$ & $\begin{array}{c}23 \\
(25,8 \%)\end{array}$ & $\begin{array}{c}50 \\
(56,2 \%)\end{array}$ & $\begin{array}{c}16 \\
(18 \%)\end{array}$ \\
\hline \multirow[t]{2}{*}{7} & or Display & & & & & \\
\hline & $\begin{array}{l}\text { Tata letak barang } \\
\text { dengan tersusun } \\
\text { produk. }\end{array}$ & $\begin{array}{c}0 \\
(0 \%)\end{array}$ & $\begin{array}{c}24 \\
(27 \%)\end{array}$ & $\begin{array}{c}35 \\
(39,3 \%)\end{array}$ & $\begin{array}{c}26 \\
(29,2 \%)\end{array}$ & $\begin{array}{c}2 \\
(4,5 \%)\end{array}$ \\
\hline 8 & $\begin{array}{l}\text { Display barang tersusun dengan } \\
\text { tempatnya. }\end{array}$ & $\begin{array}{c}0 \\
(0 \%)\end{array}$ & $\begin{array}{c}21 \\
(23,6 \%)\end{array}$ & $\begin{array}{c}41 \\
(46,1 \%)\end{array}$ & $\begin{array}{c}23 \\
(25,8 \%)\end{array}$ & $\begin{array}{c}4 \\
(4,5 \%)\end{array}$ \\
\hline
\end{tabular}

Tabel Distribusi Frekuensi Variabel Barang Yang Ditawarkan $\left(X_{2}\right)$

\begin{tabular}{|c|c|c|c|c|c|c|}
\hline No & Pernyataan & $\frac{\text { STS }}{(1)}$ & $\begin{array}{l}\text { TS } \\
\text { (2) }\end{array}$ & $\frac{N}{(3)}$ & $\frac{S}{(4)}$ & $\begin{array}{l}\text { SS } \\
(5)\end{array}$ \\
\hline \multirow[t]{3}{*}{1} & Sampel Produ & & & & & \\
\hline & $\begin{array}{llr}\begin{array}{l}\text { Minimarket } \\
\text { sampel }\end{array} & \begin{array}{l}\text { OMl } \\
\text { produk }\end{array} & \text { memberikan } \\
\text { pelanggan. } & & \\
\end{array}$ & $\begin{array}{c}0 \\
(0 \%)\end{array}$ & $\begin{array}{c}0 \\
(0 \%)\end{array}$ & $\begin{array}{c}21 \\
(23,6 \%)\end{array}$ & $\begin{array}{c}36 \\
(40,4 \%)\end{array}$ & $\begin{array}{c}32 \\
(36 \%)\end{array}$ \\
\hline & Kupon & & & & & \\
\hline 2 & $\begin{array}{l}\text { Pelanggan akan mendapat kupon } \\
\text { undian bila ada promo akan } \\
\text { produk tertentu. }\end{array}$ & $\begin{array}{c}0 \\
(0 \%)\end{array}$ & $\begin{array}{c}2 \\
(2,2 \%)\end{array}$ & $\begin{array}{c}18 \\
(20,2 \%)\end{array}$ & $\begin{array}{c}43 \\
(48,3 \%)\end{array}$ & $\begin{array}{c}26 \\
(29,2 \%)\end{array}$ \\
\hline 3 & $\begin{array}{l}\text { Pengembalian Tunai } \\
\text { Pelanggan yang tak merasa puas } \\
\text { dapat mengembalian akan } \\
\text { produk yang dibelinya. }\end{array}$ & $\begin{array}{c}0 \\
(0 \%)\end{array}$ & $\begin{array}{c}5 \\
(5,6 \%)\end{array}$ & $\begin{array}{c}20 \\
(22,5 \%)\end{array}$ & $\begin{array}{c}43 \\
(48,3 \%)\end{array}$ & $\begin{array}{c}21 \\
(23,6 \%)\end{array}$ \\
\hline 4 & $\begin{array}{l}\text { Harga Khusus } \\
\text { Minimarket OMI sering } \\
\text { memberikan potongan harga } \\
\text { kusus barang kepada pelanggan. }\end{array}$ & $\begin{array}{c}0 \\
(0 \%)\end{array}$ & $\begin{array}{c}11 \\
(12,4 \%)\end{array}$ & $\begin{array}{c}51 \\
(57,3 \%)\end{array}$ & $\begin{array}{c}21 \\
(23,6 \%)\end{array}$ & $\begin{array}{c}6 \\
(6,7 \%)\end{array}$ \\
\hline 5 & $\begin{array}{l}\text { Premi } \\
\text { Pihak Minimarket OMI } \\
\text { memberikan potongan harga bagi }\end{array}$ & $\begin{array}{c}0 \\
(0 \%)\end{array}$ & $\begin{array}{c}8 \\
(9 \%)\end{array}$ & $\begin{array}{c}51 \\
(57,3 \%)\end{array}$ & $\begin{array}{c}29 \\
(32,6 \%)\end{array}$ & $\begin{array}{c}1 \\
(1,1 \%)\end{array}$ \\
\hline
\end{tabular}




\begin{tabular}{|c|c|c|c|c|c|c|}
\hline & $\begin{array}{l}\text { pelanggan yang membeli secara } \\
\text { kredit. }\end{array}$ & & & & & \\
\hline \multirow[t]{2}{*}{6} & Barang Khusus Iklan & & & & & \\
\hline & $\begin{array}{l}\text { Minimarket OMI memberikan } \\
\text { diskon atas barang yang berlebel } \\
\text { akan barang khusus agar pembeli } \\
\text { mengetahuinya. }\end{array}$ & $\begin{array}{c}0 \\
(0 \%)\end{array}$ & $\begin{array}{c}8 \\
(9 \%)\end{array}$ & $\begin{array}{c}52 \\
(58,4 \%)\end{array}$ & $\begin{array}{c}19 \\
(21,3 \%)\end{array}$ & $\begin{array}{c}10 \\
(11,2 \%)\end{array}$ \\
\hline \multirow[t]{2}{*}{7} & Undian Produk & & & & & \\
\hline & $\begin{array}{l}\text { Minimarket OMI melakukan } \\
\text { pengundian akan produk-produk } \\
\text { tertentu. }\end{array}$ & $\begin{array}{c}0 \\
(0 \%)\end{array}$ & $\begin{array}{c}12 \\
(13,5 \%)\end{array}$ & $\begin{array}{c}50 \\
(56,2 \%)\end{array}$ & $\begin{array}{c}14 \\
(15,7 \%)\end{array}$ & $\begin{array}{c}13 \\
(14,6 \%)\end{array}$ \\
\hline 8 & $\begin{array}{l}\text { Membership } \\
\text { Minimarket } \quad \text { OMI telah } \\
\text { memberikan } \\
\text { pelanggan belanja. }\end{array}$ & $\begin{array}{c}0 \\
(0 \%)\end{array}$ & $\begin{array}{c}0 \\
(0 \%)\end{array}$ & $\begin{array}{c}23 \\
(25,8 \%)\end{array}$ & $\begin{array}{c}50 \\
(56,2 \%)\end{array}$ & $\begin{array}{c}16 \\
(18 \%)\end{array}$ \\
\hline
\end{tabular}

Tabel Distribusi frekuensi Variabel Loyalitas Pelanggan (Y)

\begin{tabular}{|c|c|c|c|c|c|c|}
\hline No & Pernyataan & $\begin{array}{l}\text { STS } \\
(1)\end{array}$ & $\begin{array}{l}\text { TS } \\
(2)\end{array}$ & $\begin{array}{l}N \\
(3)\end{array}$ & $\begin{array}{l}S \\
(4)\end{array}$ & $\begin{array}{l}\text { SS } \\
\text { (5) }\end{array}$ \\
\hline 1 & $\begin{array}{l}\text { Pembelian Ulang } \\
\text { Pelanggan kembali } \\
\text { menggunakan jasa Minimarket } \\
\text { OMI Koperasi Univ. PGR } \\
\text { Palembang untuk membeli } \\
\text { sesuatu. }\end{array}$ & $\begin{array}{l}0 \\
(0 \%)\end{array}$ & $\begin{array}{l}18 \\
(20,2 \%)\end{array}$ & $\begin{array}{l}46 \\
(51,7 \%)\end{array}$ & $\begin{array}{l}22 \\
(24,7 \%)\end{array}$ & $\begin{array}{l}3 \\
(3,4 \%)\end{array}$ \\
\hline 2 & $\begin{array}{l}\text { Pelanggan menggunakan jasa } \\
\text { Minimarket OMI Koperasi Univ. } \\
\text { PGRI secara teratur. }\end{array}$ & $\begin{array}{l}0 \\
(0 \%)\end{array}$ & $\begin{array}{l}15 \\
(16,9 \%)\end{array}$ & $\begin{array}{l}47 \\
(52,8 \%)\end{array}$ & $\begin{array}{l}21 \\
(23,6 \%)\end{array}$ & $\begin{array}{l}6 \\
(6,7 \%)\end{array}$ \\
\hline & Pembelian antar Produk & & & & & \\
\hline 3 & $\begin{array}{l}\text { Pelanggan menggunakan jasa } \\
\text { Minimarket OMl Koperasi Univ. } \\
\text { PGRI Palembang } \\
\text { keperluan lain. }\end{array}$ & $\begin{array}{l}0 \\
(0 \%)\end{array}$ & $\begin{array}{l}1 \\
(1,1 \%)\end{array}$ & $\begin{array}{l}16 \\
(18 \%)\end{array}$ & $\begin{array}{l}53 \\
(59,6 \%)\end{array}$ & $\begin{array}{l}19 \\
(21,3 \%)\end{array}$ \\
\hline 4 & $\begin{array}{l}\text { Pelanggan tidak hanya } \\
\text { menggunakan produk/jasa utama. } \\
\text { Mereferensikan pada orang lain }\end{array}$ & $\begin{array}{l}0 \\
(0 \%)\end{array}$ & $\begin{array}{l}1 \\
(1,1 \%)\end{array}$ & $\begin{array}{l}10 \\
(22,5 \%)\end{array}$ & $\begin{array}{l}61 \\
(68,5 \%)\end{array}$ & $\begin{array}{l}7 \\
(7,9 \%)\end{array}$ \\
\hline 5 & $\begin{array}{l}\text { Pelanggan merekomendasikan } \\
\text { jasa Minimarket OMI Koperasi } \\
\text { Univ. PGRI Palembang pada } \\
\text { orang lain. }\end{array}$ & $\begin{array}{l}0 \\
(0 \%)\end{array}$ & $\begin{array}{l}1 \\
(1,1 \%)\end{array}$ & $\begin{array}{l}19 \\
(21,3 \%)\end{array}$ & $\begin{array}{l}54 \\
(60,7 \%)\end{array}$ & $\begin{array}{l}15 \\
(16,9 \%)\end{array}$ \\
\hline 6 & $\begin{array}{l}\text { Pelanggan menyampaikan hal- } \\
\text { hal positif pada orang lain. }\end{array}$ & $\begin{array}{l}0 \\
(0 \%)\end{array}$ & $\begin{array}{l}5 \\
(5,6 \%)\end{array}$ & $\begin{array}{l}17 \\
(19,1 \%)\end{array}$ & $\begin{array}{l}53 \\
(59,6 \%)\end{array}$ & $\begin{array}{l}14 \\
(15,7 \%)\end{array}$ \\
\hline 7 & 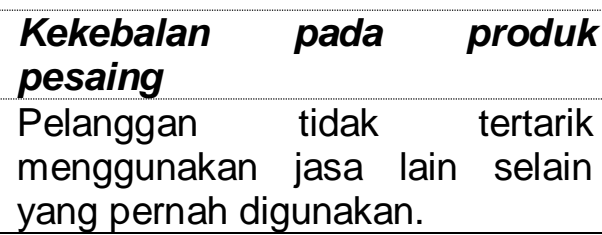 & $\begin{array}{l}0 \\
(0 \%)\end{array}$ & $\begin{array}{l}8 \\
(9 \%)\end{array}$ & $\begin{array}{l}52 \\
(58,4 \%)\end{array}$ & $\begin{array}{l}19 \\
(21,3 \%)\end{array}$ & $\begin{array}{l}10 \\
(11,2 \%)\end{array}$ \\
\hline
\end{tabular}




\begin{tabular}{llrllll}
\hline 8 & Pelanggan percaya & 0 & 13 & 48 & 26 & 2 \\
& menggunakan jasa Minimarket & $(0 \%)$ & $(14,6 \%)$ & $(53,9 \%)$ & $(29,2 \%)$ & $(2,2 \%)$ \\
& OMl Koperasi Univ. PGRI & & & & \\
Palembang karena harganya & & & & \\
lebih murah dari lain. & & & & \\
\hline
\end{tabular}

Tabel Hasil Uji Normalitas Data One-Sample Kolmogorov-Smirnov Test

\begin{tabular}{llccccc}
\hline & & $\begin{array}{c}\text { Pelayanan } \\
\left(\mathrm{X}_{1}\right)\end{array}$ & $\begin{array}{c}\text { Barang } \\
\text { Yang } \\
\text { Ditawarkan } \\
\left(\mathrm{X}_{2}\right)\end{array}$ & $\begin{array}{c}\text { Suasana } \\
\left(\mathrm{X}_{3}\right)\end{array}$ & $\begin{array}{c}\text { Harga } \\
\left(\mathrm{X}_{4}\right)\end{array}$ & $\begin{array}{c}\text { Loyalitas } \\
\text { Konsumen } \\
(\mathrm{Y})\end{array}$ \\
$\mathrm{N}$ & & 90 & 90 & 90 & 90 & 90 \\
\hline \multirow{2}{*}{ Normal Parameters } & Mean & 2.754 & 2.846 & 3.219 & 3.019 & 3.019 \\
\cline { 2 - 7 } & $\begin{array}{l}\text { Std. } \\
\text { Deviation }\end{array}$ & 0.413 & 0.524 & 0.696 & 0.496 & 0.496 \\
\hline Most Extreme & Absolute & 0.098 & 0.106 & 0.152 & 0.052 & 0.052 \\
\cline { 2 - 8 } Differences & Positive & 0.103 & 0.106 & 0.152 & 0.052 & 0.052 \\
\hline Kolmogorov-Smirnov Z & Negative & -0.057 & -0.060 & -0.046 & -0.042 & -0.042 \\
\hline Asymp. Sig. (2-tailed) & & 1.015 & 1.001 & 0.778 & 0.694 & 0.494 \\
\hline
\end{tabular}

Tabel Hasil Analisis Jalur Persamaan Struktural

\begin{tabular}{|c|c|c|c|c|c|c|}
\hline \multirow{2}{*}{\multicolumn{2}{|c|}{ Model }} & \multicolumn{2}{|c|}{$\begin{array}{l}\text { Unstandardized } \\
\text { Coefficients }\end{array}$} & \multirow{2}{*}{$\begin{array}{l}\text { Standardized } \\
\text { Coefficients } \\
\text { Beta }\end{array}$} & \multirow[t]{2}{*}{$\mathrm{t}$} & \multirow[t]{2}{*}{ Sig. } \\
\hline & & $B$ & Std. Error & & & \\
\hline \multirow{6}{*}{1} & (Constant) & -.068 & .282 & & -.241 & 810 \\
\hline & Pelayanan $\left(X_{1}\right)$ & .527 & .074 & .552 & 7.081 & .000 \\
\hline & Barang & & & & & \\
\hline & Ditawarkan $\left(\mathrm{X}_{2}\right)$ & .348 & .075 & .362 & 4.643 & .000 \\
\hline & Suasana $\left(X_{3}\right)$ & .345 & .072 & .442 & 4.705 & .000 \\
\hline & Harga $\left(X_{4}\right)$ & .351 & .073 & 473 & 4.920 & .000 \\
\hline
\end{tabular}

maka estimasi fungsi regresi diperoleh adalah sebagai berikut:

$$
\begin{aligned}
& Y=B_{1} X_{1}+B_{2} X_{2}+B_{3} X_{3}+B_{4} X_{4}+e_{1} \\
& Y=0,552 X_{1}+0,362 X_{2}+0,442 X_{3}+0,473 X_{4}+e_{1}
\end{aligned}
$$

\begin{tabular}{|c|c|c|c|}
\hline \multirow[b]{2}{*}{ Model } & Coefficien & \multicolumn{2}{|c|}{ Collinearity Statistiks } \\
\hline & & Tolerance & VIF \\
\hline 1 & $\begin{array}{l}\text { (Constant) } \\
\text { Pelayanan }\left(X_{1}\right) \\
\text { Barana Yana Ditawarkan }\end{array}$ & .986 & 1.015 \\
\hline & & .986 & 1.015 \\
\hline & Suasana $\left(X_{3}\right)$ & .989 & 1.015 \\
\hline & Harga $\left(X_{4}\right)$ & .989 & 1.015 \\
\hline
\end{tabular}

\section{Tabel Hasil Uji Multikoliniaritas}

a.Dependent Variable: Loyalitas Pelanggan 


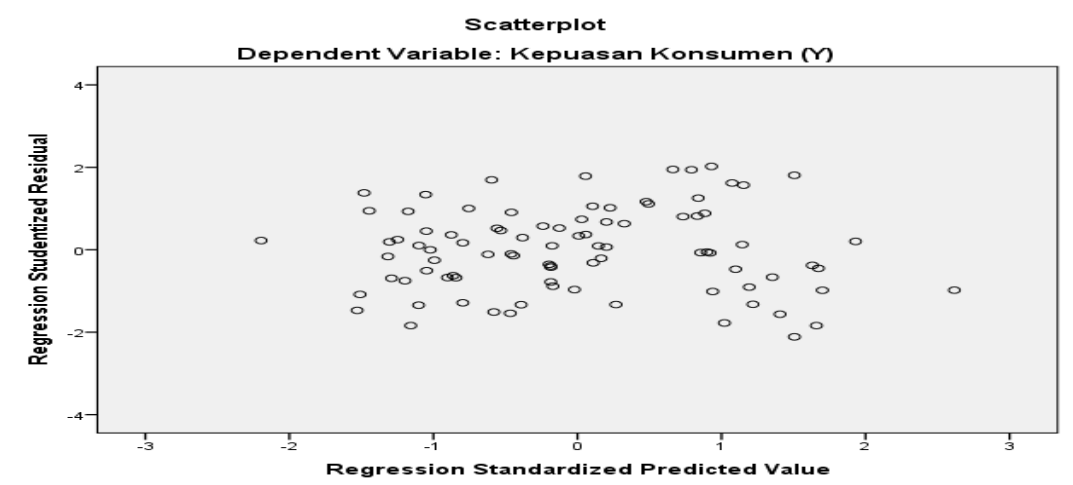

Gambar Hasil Uji Heterokedastisitas

Tabel Hasil Uji Analisis Jalur Persamaan Struktural

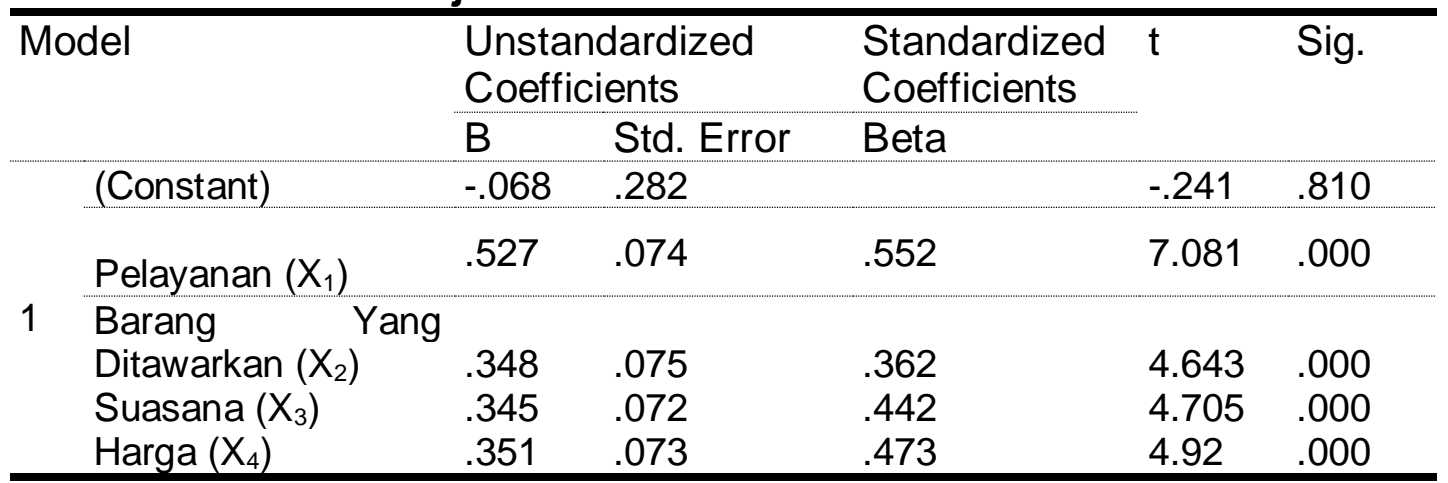

a. Dependent Variable: Loyalitas Pelanggan ( $\mathrm{Y}$ )

Tabel Pengaruh Langsung Dan Pengaruh Tidak Langsung Antar Variabel

\begin{tabular}{cccc}
\hline $\begin{array}{c}\text { Pengaruh } \\
\text { Variabel }\end{array}$ & $\begin{array}{c}\text { Pengaruh } \\
\text { Langsung }\end{array}$ & $\begin{array}{c}\text { Pengaruh tidak } \\
\text { langsung melalui } \\
\text { Loyalitas Pelanggan }\end{array}$ & $\begin{array}{c}\text { Pengaruh } \\
\text { Total }\end{array}$ \\
\hline $\mathrm{X}_{1}$ ke $\mathrm{Y}$ & 0,552 & - & 0,552 \\
$\mathrm{X}_{2}$ ke $\mathrm{Y}$ & 0,362 & - & 0,362 \\
$\mathrm{X}_{3}$ ke $\mathrm{Y}$ & 0,442 & - & 0,442 \\
$\mathrm{X}_{4}$ ke $\mathrm{Y}$ & 0,473 & - & 0,473 \\
\hline
\end{tabular}

Tabel Hasil Uji Model Summary Atmosfer Toko dan Promosi Penjualan Terhadap Loyalitas Pelanggan

\begin{tabular}{lllll}
\hline Model & $R$ & $R$ Square & $\begin{array}{l}\text { Adjusted } \\
\text { Square }\end{array}$ & $\begin{array}{l}\text { Std. Error of } \\
\text { the Estimate }\end{array}$ \\
\hline 1 & $0.696^{\mathrm{a}}$ & 0.484 & 0.472 & 0.36355 \\
\hline
\end{tabular}

a. Predictors: (Constant), Harga (X4), Suasana (X3), Barang Yang Ditawarkan (X2), Pelayanan (X1)

E. KESIMPULAN DAN SARAN

1) Kesimpulan

a) Terdapat pengaruh Pelayanan terhadap loyalitas pelanggan di Minimarket OMI Koperasi Keluarga Univ. PGRI Palembang. 
b) Terdapat pengaruh barang yang ditawarkan terhadap loyalitas pelanggan di Minimarket OMI Koperasi Keluarga Univ. PGRI Palembang.

c) Terdapat pengaruh suasana terhadap loyalitas pelanggan di Minimarket OMI Koperasi Keluarga Univ. PGRI Palembang.

d) Terdapat pengaruh antara harga terhadap loyalitas pelanggan di Minimarket OMI Koperasi Keluarga Univ. PGRI Palembang.

e) Terdapat pengaruh antara pelayanan, barang yang ditawarkan, suasana toko dan harga terhadap loyalitas pelanggan di Minimarket OMI Koperasi Keluarga Univ. PGRI Palembang.

\section{2) Saran}

a) Minimarket OMI Koperasi Keluarga Univ. PGRI Palembang perlu berbenah diri dalam peningkatan pelayanan toko bagi pelanggan. Pegawai toko harus ditambah guna mengawasi dan menjaga produk yang dijual agar lebih meningkatkan labanya.

b) Minimarket OMI Koperasi Keluarga Univ. PGRI Palembang hendaknya memberikan promosi berupa diskon harga dan bonus untuk barang yang dijual di saat pengunjung sepi, misalnya awal bulan ramadhan, sebaiknya memberikan potongan harga.

c) Kepuasan pelanggan seharusnya dapat membentuk loyalitas pelanggan, rasa loyal pelanggan menggunakan jasa sebaiknya pihak Minimarket OMI Koperasi Keluarga Univ. PGRI Palembang lebih gencar melakukan promosi produk-produk terbaru yang ditawarkan.

\section{DAFTAR PUSTAKA}

Alqifari. 2016. Statistik Induktif, Jakarta: UPP STIM YKPN

Berman, B \& Evans, Jr 2017 Retail Manajemen: A Strategic Approach . Prentice Hall

Creswell \& John, W. 2013 Research Desaign Qualitative \& Quantitative Approaches, Jakarta: Penerbit KIK Press

Griffin, Jill. 2015. Customer Loyality: Menumbuhkan Dan Mempertahankan Kesetiaan Pelanggan. Jakarta: Erlangga

Hendri, Ma'ruf , 2015, Pemasaran Ritel, PT. Gramedia Pustaka Utama, Jakarta.

Kotler, P. 2017. Dasar-dasar Pemasaran. Edisi 9 Jilid 1 dan 2. Jakarta. Indonesia:PT.Indeks Kelompok Gramedia

2012. yang diterjemahkan oleh AB. Susanto, 2012.

Manajemen Pemasaran, PT. Prenhalindo, Yogyakarta.

Riadi, Edi, 2016, Statistik Penelitian Analisis Manual Dan IBM SPSS, Yogyakarta: Andi

Sugiyono. (2017). Statistik untuk Penelitian. (cetakan.20). Bandung, Indonesia: Alfa Beta. 
Supranto. M.A. 2016. Pengukuran Tingkat Kepuasan Pelanggan Untuk Menaikkan Pangsa Pasar. Jakarta: Rineka Cipta.

2015, Dinamika Pemasaran, PT. Raja Grafindo Persada, Jakarta

Tjahyadi, RA. 2016. Brand Trust Dalam Konteks Loyalitas Merek: Peran Karakter Merek. Jurnal Manajemen, 6:65-78

Yavas, U \& Babakus, E. 2013. Retail Store Loyalty: A Comparison of Two Customer Segments: International Journal of Retail and Distribution Manajemen, 37:6:477-492 